\title{
Optimization of the composition of the harvesting and transport complex
}

\author{
G.A. Iovlev, I.I. Goldina, A.A. Sadov ${ }^{*}$, and T.B. Popova \\ Ural State Agrarian University, Yekaterinburg, Russia
}

\begin{abstract}
The purpose of the article is to obtain additional knowledge, identify patterns of optimization of the harvesting and transport complex and use this knowledge and patterns in further practical activities. The study used methods of classical mathematics, observation, comparison, measurement, and experiment. As a result, the mathematical expectation of "time to fill the hopper" was calculated and justified, the grain yield was calculated and determined by the time of filling the hopper, the number of vehicles was justified by yield and distance to the warehouse from the field. According to the time of loading of the vehicle, coefficients were developed and determined that determine the efficiency of transport work during the transportation of harvest. The obtained research results have theoretical and practical significance for application in agricultural organizations of the Russian Federation, which is implemented in the methodological recommendations for optimization of the composition of harvesting and transport complexes.
\end{abstract}

\section{Introduction}

To intensify the harvesting process, the organization of work by harvesting and transport complexes has recently been used. Their mass use in agricultural production has shown high efficiency as a result of reducing the time of harvesting, reducing the number of combines and cars engaged in the harvesting process (other vehicles), improving the quality of work, improving the use of arable land.

High economic efficiency of agricultural machinery as part of harvesting and transport complexes is due to the correct deployment, in relation to specific production conditions. Production conditions are the cultivated crop, its yield, ripeness (readiness stage); the distance of the field from the warehouse; the condition of roads; the technical condition of combines and transport equipment; the capacity and technical condition of the grain drying and sorting facilities, etc. The optimal structure is determined by the rational formation of a reasonable composition of technical means of production (combines and transport), as well as auxiliary means (mobile technological equipment for maintenance and troubleshooting operations).

The use of harvesting and transport complexes allows you to increase the efficiency of high-performance machines. One harvesting and transport complex during grain harvesting accounts for 2.5-3.0 thousand hectares.

\footnotetext{
* Corresponding author: artemsadov@ya.ru
} 
In the course of the research, information on the topic "Optimization of the composition of the harvesting and transport complex" was systematized. Work was carried out to collect statistical data on the work of harvesting and transport complexes over the past three years. Based on the results of this work, recommendations have been prepared for completing harvesting and transport complexes. The essence of the work is as follows: the grain yield is determined by the time the hopper of the combine harvester is filled, the yield is determined by the number of necessary vehicles for transporting grain to the warehouse; depending on the distance to the warehouse, when determining the number of vehicles, correction coefficients are applied.

The development of this topic began with the study of the possibility of application of the probability theory to identify certain patterns of occurrence of a result in a test or study. Probability theory is used to form the optimal composition of the harvesting and transport complex. One of the most important concepts of probability theory is the concept of a random variable/value, which can be discrete or continuous $[1,2]$.

In our case, a discrete value is the number of bunkers collected by various combine harvesters over a certain period of time. Continuous value - time of one hopper filling, waiting time for the vehicle to unload the hopper. Here are the numerical characteristics of a random variable - mathematical expectation, variance and mean square deviation.

The hypothesis of the study. Improving the efficiency of the harvesting and transport complex in farms can be provided by implementing a set of technological and technical solutions based on the use of elements of probability theory, i.e. methods of mathematical analysis and mathematical statistics.

To reveal the hypothesis of the study, the goal was set to justify the optimal parameters of the harvesting and transport complex for grain crops harvesting.

Research objectives:

1. Development of table forms for the following information collection:

1.1. Time to fill the hopper.

1.2. Vehicle waiting time.

1.3. Time to unload the hopper into the vehicle.

1.4. Driving time of the combine harvester to the fold.

1.5. Waiting time for the car to load after returning from the warehouse.

1.6. Driving time up to the 1 st combine harvester.

1.7. Unloading time of the 1 st combine harvester.

1.8. Waiting time of loading of the $\mathrm{n}$-th hopper.

1.9. Driving time up to the $\mathrm{n}$-th combine harvester.

1.10. Unloading time of the $\mathrm{n}$-th combine harvester.

1.11. Transport cycle time.

2. Calculatation: mathematical expectation, variance and mean square deviation of indicators.

3. Calculation of the yield of the harvested crop.

4. Calculation of the number of vehicles needed to ensure optimal operation of the harvesting unit.

5. Development of recommendations for determining the optimal number of vehicles for transporting grain from combines.

The topic "Optimization of the composition of the harvesting and transport complex" is of particular scientific interest, due to the fact that modern agricultural machinery, in particular grain harvesters, is an energy-saturated, expensive equipment. Its ineffective use leads to high unproductive costs. The most common combine harvester of Russian production "ACROS-580 (585)" has a 300 HP engine, Claas Tucano 450, John Deere W650, Palesse GS 12 from 306 to 330 HP. The cost of Acrosa - 8834 thousand rubles, Belarusian combines 7729 thousand rubles, Claas Tucano 450 - 15732 thousand rubles. 
When developing this topic, domestic and foreign scientists adhere to the main trend: minimum costs and losses when harvesting grain crops with the appropriate yield. Many of them consider the main problem in determination of the optimal parameters of HTC imperfection of transport services. Direct transportation (combine harvester - vehicle warehouse) is less efficient than using mobile compensators (grain storage). As a result of inefficient transport work, the productivity of the entire HTC is reduced. Another problem that researchers consider no less important is the reduction of the combine harvester fleet, the aging of the fleet, and as a result, an increase in the share of faulty machines, an increase in the average load on the harvester, harvesting time and grain loss from self-shedding. All this complicates the issues of optimization of the composition of the harvesting and transport complex.

The main topics that scientists are working on in this area are the following:

- increasing the efficiency of combine harvesters by optimizing energy consumption;

- strategic directions for grain crops harvesting;

- organization of harvesting and transport complexes;

- strategy for the long-term development of grain harvesting mechanization;

- optimization of the harvesting and transport process of grain crops harvesting using a mobile loader;

- analysis of existing methods and criteria for evaluating the effectiveness of production processes.

Main part. On the subject of this article, the authors have published the following works:

1. Formation of the optimal composition of the harvesting complex using probability theory [1]. This article discusses the following issues: basic concepts and definitions of probability theory are given; distribution laws of a discrete random variable are provided; numerical characteristics of a random variable are introduced; specific discrete value was determined for our study - the number of hoppers collected by the combine harvester for a certain period of time, continuous values - the time of one hopper filling, the waiting time of the vehicle for the hopper unloading and others; data for calculating the intensity of receipt of requirements for filled hoppers unloading were determined; data for calculating the intensity of transport services were defined; tables that reflect the receipt of requirements for filled bunkers unloading and transport services are compiled and filled in; charts, determining distribution laws for the following indicators are analyzed, compiled: "filling time of the combine harvester hopper", "waiting time for the vehicle", "total time for 1 cycle of the combine harvester (time for hopper filling, waiting time for vehicle, time for hopper unloading into the transport means, travel time of combine harvester to fold)", "waiting time for the vehicle to load after returning from the warehouse", "transport cycle time"; numerical characteristics of random values of the main indicators are calculated; according to the tables and charts, the work of the HTC is analyzed. As a result, it was concluded that according to experimental data, based on the "time of hopper filling", it is possible to calculate and monitor the current yield of the harvested crop, which also makes it possible to quickly optimize the harvesting complex.

2. Operational optimization of the harvesting complex [2]. The article considers the following issues: the possibility of application of probability theory to form the optimal composition of the harvesting complex; the operation of the harvesting and transport complex with an increased number of cars for transporting grain is analyzed; a formula is offered and the current yield of the harvested crop is calculated; the dependence of the filling time of the combine harvester hopper on the yield of agricultural crops (wheat) is deduced and a chart of the ratio of productivity and time of filling the combine harvested hopper is presented. The authors concluded that using the dependencies and the chart of the ratio of yield and time of the hopper filling, the work of the harvesting complex can be quickly controlled, i.e., certain 
corrective actions can be made, both by the number of combine harvesters and by the number of vehicles.

3. Operational management of the harvesting and transport complex [3]. The following questions were considered: the possibility of managing the productivity of the harvesting and transport complex through the use of elements of the probability theory (mathematical analysis) for all types of work on harvesting and harvesting feeds is explained; the formula is proposed and the number of vehicles necessary to ensure the optimal (without downtime) operation of the harvesting complex is calculated; indicators are calculated and the chart of the dependence of the number of vehicles to ensure optimal operation of the harvesting complex, depending on yield, is plotted; correction factors for determination of the number of vehicles when servicing the harvesting complex at various distances from the field to the warehouse are experimentally determined; the dependence of the cost of transportation on the load time of the vehicle is derived (data are presented in tables); it is concluded that the use of combine harvesters is efficient.

Conclusion. The topic of optimization of the work of harvesting and transport complexes has been of interest for a long time and caused by many reasons. Let's look at the main publications on the research topic.

Chulkov A.V. in his work "Improving the efficiency of the harvesting and transport complex on the basis of mobile vehicles with interchangeable bodies during grain crops harvesting" [4] considers the organization of the harvesting and transport process through strict consistency of vehicles with combines. If there is no such consistency, the productivity of the harvesting and transport complex is reduced. The author considers the organization of the transport process as a priority in improving the efficiency of the harvesting and transport complex. One of the ways to solve this problem is to use transshipment technologies based on mobile vehicles with interchangeable bodies.

The team of authors Muzylev D.A., Kravtsov A.G., Karnaukh N.V., Berezhnaya N.G., Kutya O.V. in their work "Development of methods for selection of conditions for interaction of grain harvesting and transport complexes" [5] considers the combine harvester as a basic element of the entire harvesting and transport complex, it also determines the size and structure of the entire transport complex. The combine harvester must correspond to the yield of grain crops and the areas of agricultural organizations. The success of the harvesting process depends on the technical and operational characteristics of the selected combine harvester.

Lunyakin V.N. in his work "Optimization of the harvesting and transport process of grain crops harvesting using a mobile loader" [6] points to the complex conditions for the assembly and transport process. More severe conditions during assembly operations often cause vehicles to be inconsistent with harvesters. As a result, the productivity of the harvesting and transport complex is reduced. The author also considers the organization of the transport process through the use of a mobile loader to be the main factor in improving the efficiency of the harvesting and transport complex. As a result, the downtime of combine harvesters will decrease, and the productivity of vehicles will increase.

Abaev V.V. in the article "Improving the efficiency of the optimal system of grain harvesting technologies" [7] says that the modern technology of combine harvesting of grain crops is labor-intensive, energy-intensive and does not allow to solve the main task - to minimize crop losses, downtime of the entire harvesting complex due to the violation of the rhythm of the process, to harvest in optimal terms. It is necessary to finalize the methodological foundations of the type and structure of the combine fleet optimization and a rational combination of alternative options for resource-saving harvesting technologies. We need new concepts of creation of resource-saving technologies for harvesting taking into account environmental safety, new methods of harvesting on the basis of multi-purpose 
harvesting and tillage outfits (HTO), as well as scientific and methodological bases for effective interaction of all parts of the harvesting complex.

The scientific problem is to develop methods for substantiation and synthesizing of technological operations, technical means, the optimal type-size range (type) and structure of the combine fleet, and the optimal system of resource-saving harvesting technologies. There is a need to improve the multi-level system approach based on modeling of production processes of harvesting and transport complexes according to a single criterion of resource saving.

It also provides for the use of grain transfer hoppers.

Mikhailov M.R. in his work "Optimization of the use of combine harvesters by reliability parameters" [8] offers a method for optimization of the seasonal load, using the concept of "resource groups" of combine harvesters of the technological complex, taking into account their technical condition and operating conditions. Resource groups are formed based on operating costs for pre-season preparation of combines. For the method of distribution of combine harvesters by resource groups, at the minimum operating costs for pre-season preparation of machines, a mathematical model is used to optimize the distribution of seasonal load for resource groups of the combine harvester fleet.

Barnagyan V.S. in the work "Increasing the efficiency of using agricultural machinery of machine-technological stations" [9] justified the ways to improve the efficiency of use, the boundaries of effective use of harvesting and transport units and complexes within the MTS. A model of machine use in farms was developed, taking into account the influence of environmental factors on the efficiency of harvesting units within the MTS. The calculation of the expected potential yield of agricultural crops, taking into account the current demand, prices for cereals, fue and the exchange rate of the dollar to the ruble was made on the basis of a SWOT analysis. Taking into account these market indicators and other factors will make it possible to more reasonably plan the production of grain harvesters, to recognize the technological limits of the effectiveness of organizational forms of combines using within the MTS.

The research made it possible to determine the ways to reduce operating costs and offer an adequate model for the formation of harvesting units within the MTS. Data from the MIS system of Russia are recommended for completing units within MTS and determining the brand composition.

Shepelev V.D. in his work "Justification of technical and technological consistency of the processes of harvesting and post-harvest processing of grain" [10] considers the harvesting process from the point of view of equality of productivity of harvesting, transport and grain cleaning lines, therefore, an important reserve for reducing costs and crop losses is to ensure consistency in the interaction of all parts of the harvesting process. The current production situation calls for improving methodological approaches to the design of the technological system based on a single complex of harvesting, transportation and post-harvest processing of grain. Stabilization of the operation of the harvesting and grain cleaning lines is facilitated by the use of compensating and reserve elements (compensator hopper, reserve grain cleaning machines) of the technological process, the parameters of which must be determined taking into account specific natural and industrial conditions. The result of the research is the development of an economic and mathematical model that allows to design harvesting and grain cleaning processes that ensure consistency and stabilization of their functioning parameters. 


\section{Materials and methods}

To form the optimal composition, the work of the harvesting and transport complex, consisting of four combine harvesters and three KAMAZ vehicles with trailers, was analyzed. Combine harvesters of the brand "ACROS-580" - 3 units, "ACROS-585" - 1 unit [11]

The following data were used to calculate the intensity of requests for filled hoppers unloading: hopper filling time; waiting time for the vehicle to unload the hopper; time of hopper unloading; driving time of the combine harvester to the fold (in case of "directly" harvesting).

To calculate the intensity of the transport service the following data were used: waiting time of the first hopper loading after returning of the vehicle from the warehouse; driving time to first combine harvester; unloading time of the first combine harvester; receipt time of the second hopper (consists of the waiting time for filling the 2 nd hopper and the driving time to the second combine harvester); unloading time of the second combine harvester; time to receive the $n$-th bunker; unloading time of the $n$-th combine harvester; transport cycle time (it consists of driving time of vehicle to the grain storage, unloading time of the vehicle, driving time of vehicle from the grain storage to the field).

Based on statistical data (a total of 319 measurements were made), the following calculations were made:

1. For the time of hopper filling - mathematical expectation $=38 \mathrm{~min}$; ; variance -29.3 $\min ^{2}$.; mean square deviation-5.4 min.

2. For the waiting time for unloading into the vehicle, the mathematical expectation is $1.7 \mathrm{~min}$.

From the point of view of the analysis of random variables, according to the intensity of receipt of requirements for filled hoppers unloading, we consider the "Filling time of the combine harvester hopper" and "Vehicle waiting time", which significantly affect the performance of the harvesting and transport complex.

Using the processed statistical data, we will plot charts and determine the law of distribution of random variables [12]. Fig. 1-3.

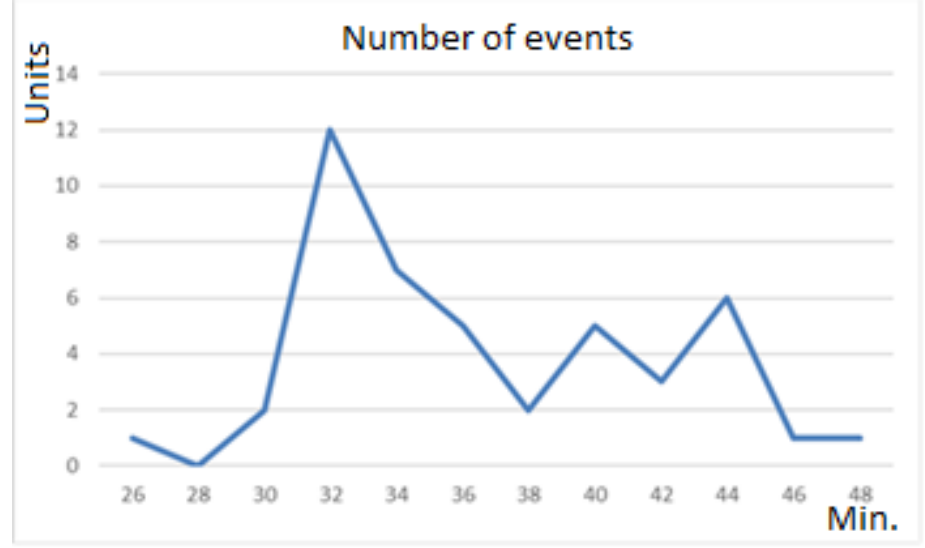

Fig. 1. Filling time of the combine harvester hopper.

Filling time of the combine harvester hopper (Fig. 1) obeys the law of normal distribution with negative asymmetry. Vehicle waiting time (Fig. 2) obeys the law of exponential distribution.

According to the intensity of requests for transport services, we will consider the following indicators: "Waiting time of loading", "Transport cycle time". The results of the analysis are presented in the form of charts shown in Fig. 3,4. 
As it can be seen from Fig. 3,4. The waiting time for the vehicle to load (Fig. 3) obeys the law of exponential distribution, the law of distribution of the transport cycle time (Fig. 4) is difficult to determine from an observed curve. To do this, it is needed to select the approval criteria. But, presumably, it will be the law of normal distribution with positive asymmetry or the Weibull-Gnedenko law.

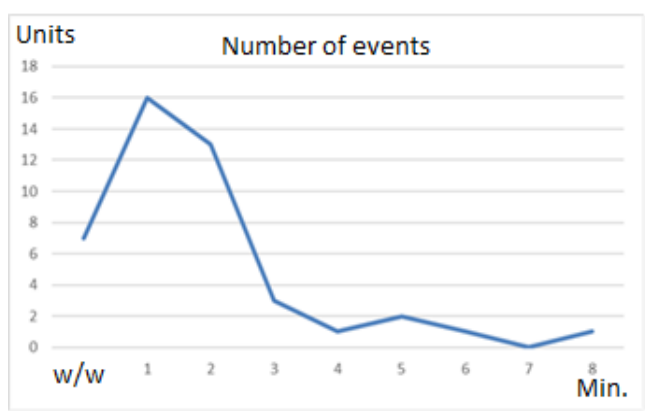

Fig. 2. Vehicle waiting time.

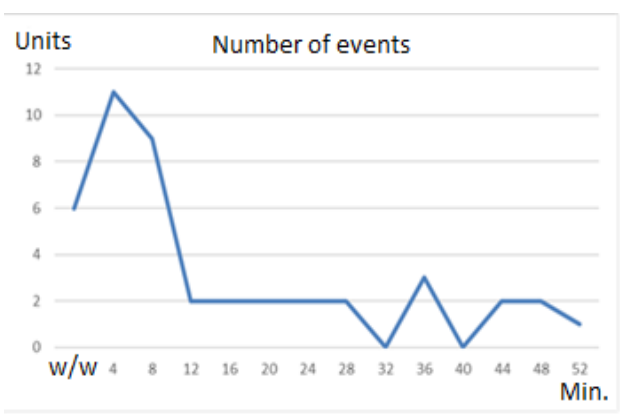

Fig. 3. Waiting time for the vehicle to load.

From the charts shown in Fig. 1-4, the following conclusion can be drawn: the waiting time for the vehicle to unload the hopper and the waiting time for the vehicle to load have opposite properties. If we take the vehicle waiting time, then the indicator "H/o (w/w)" (without waiting) has a positive meaning, because the combine harvester does not lose waiting time and immediately gets into operation. The vehicle waiting time loading with the indicator "H/o (w/w)" has a negative meaning, because at this time the combine harvester was idle waiting for the vehicle.

The results of the first work day are as follows (Fig. 3,5,6):

1. The time spent waiting for the load was 660 minutes (Fig. 3). Of these, 376 minutes is waiting for the first load when starting work and after returning from the warehouse. 158 minutes while waiting for the 4th hopper. If we remove the transport cycle time (movement from the field to the warehouse, unloading, movement from the warehouse to the field) from the total working time of cars, then downtime waiting for loading is $54.3 \%$ of the total working time.

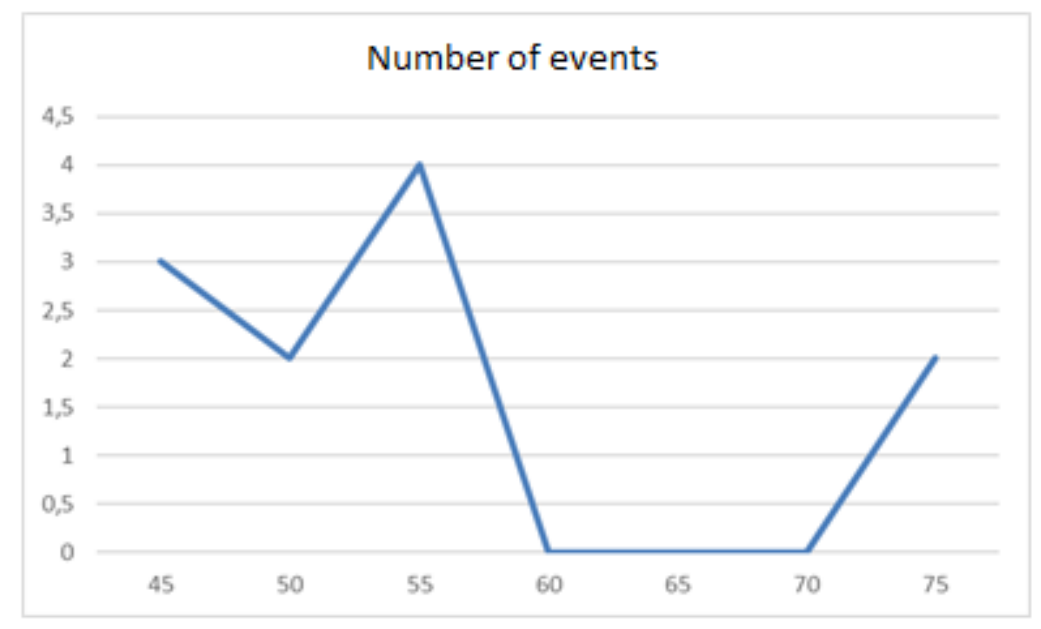

Fig. 4. Transport cycle time. 
2. To optimize the performance of the harvesting and transport complex, increase the efficiency of the HTC, using elements of probability theory, it was proposed to reduce the number of cars to two. As a result, the waiting time for unloading by combine harvester increased by 1.65 times and amounted to 2.9 minutes, compared to 1.75 minutes for three cars (Fig. 5). The waiting time for cars to load was 500 minutes, i.e. it decreased by $24.2 \%$ (Fig. 6).

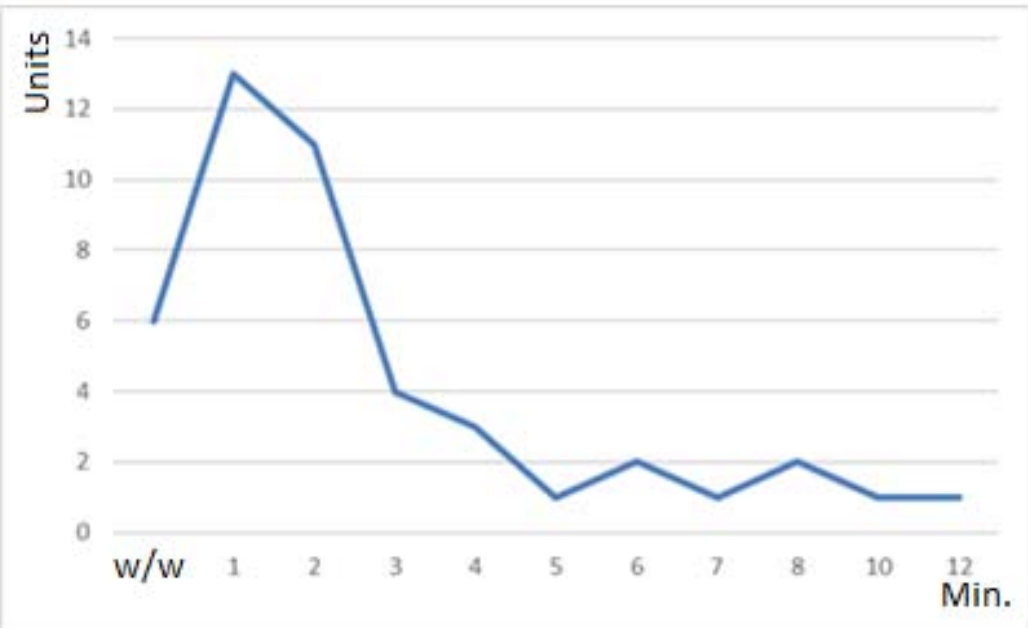

Fig. 5. Vehicle waiting time for two cars.

In addition, it was concluded that according to experimental data, based on the "time of hopper filling", it is possible to calculate and monitor the current yield of the harvested crop, which also makes it possible to quickly optimize the harvesting complex (operational management of the work).

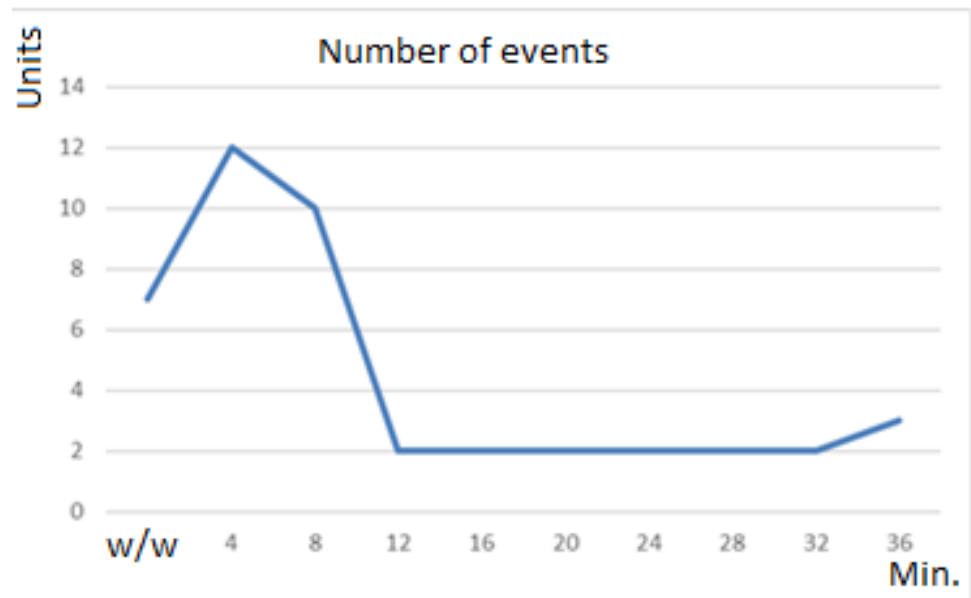

Fig. 6. Waiting for cars to load for two vehicles.

To calculate the yield, we take the following formulas:

$$
l_{\mathrm{P}}=10^{-4} \frac{Q_{H} \rho_{G} \lambda_{H}}{\mathrm{~B} \beta u}
$$

where $l_{\mathrm{W}}$ is the length of the working path of the combine hopper filling, $\mathrm{m}$ 
$Q_{\mathrm{H}}$ - hopper capacity, $\mathrm{m}^{3} \cdot Q_{\mathrm{H}}=9 \mathrm{~m}^{3}$ (from the operating instructions of the ACROS-580 combine harvester);

$P_{\mathrm{G}}-$ bulk mass of grain hopper, $\mathrm{t} / \mathrm{m}^{3}$. For barley $\rho_{\mathrm{G}} 0,67 \mathrm{t} / \mathrm{m}^{3}$.

$\Lambda_{\mathrm{H}}$ - the filling coefficient of the hopper. $\Lambda_{\mathrm{H}}=1.1$ (with a transforming roof);

$B$ - width of the cutter, m. $B=7 \mathrm{~m}$.

$u$ - yield, $\mathrm{t} / \mathrm{ha}$

$\beta$ - coefficient of cutter utilization. $B=0.96$

In addition, the length of the working path of the combine hopper filling can be calculated using the following formula:

$$
L_{\mathrm{W}}=V \times t_{H F}
$$

where $V$ is the working speed of the combine harvester when harvesting grain, $\mathrm{km} / \mathrm{h} . \quad V$ $=7-13 \mathrm{~km} / \mathrm{h}$ (from the operating instructions of the ACROS-580 combine harvester).

$T_{H F}$ - the hopper filling time, h. $t_{H F}=$ take $0.63 \mathrm{~h}$ (38 minutes), the mathematical expectation of the combine harvester hopper filling time;

By equating the formulas (1) and (2) we find the crop yield:

$$
u=10^{-4} \frac{Q_{H} \rho_{G} \lambda_{H}}{l_{W} \mathrm{~B} \beta}
$$

As a result of the calculations made on the basis of the above inputs, we get the required yield of $22.4 \mathrm{c} / \mathrm{ha}$.

Let's make similar calculations for the following time intervals of the combine harvester hopper filling: $26 ; 28 ; 30 ; 32 ; 34 ; 36 ; 38 ; 40 ; 42 ; 46 ; 48 ; 50 ; 52$. The data will be presented in the form of a table (table. 1) and a chart shown in Figure 7.

Analyzing Fig. 7 with the chart of the ratio of yield and time of combine harvester hopper filling, we see that the optimal operation of the harvesting and transport complex is influenced by three components: productivity, number of combine harvesters, number of vehicles. Under this yield, with a constant number of combine harvesters, the number of vehicles can be chosen, based on probability theory, mathematical calculations and practical experience, to ensure optimal operation of the harvesting and transport complex [13-16].

Table 1. Ratio of the time of the combine harvester hopper filling and the crop yield.

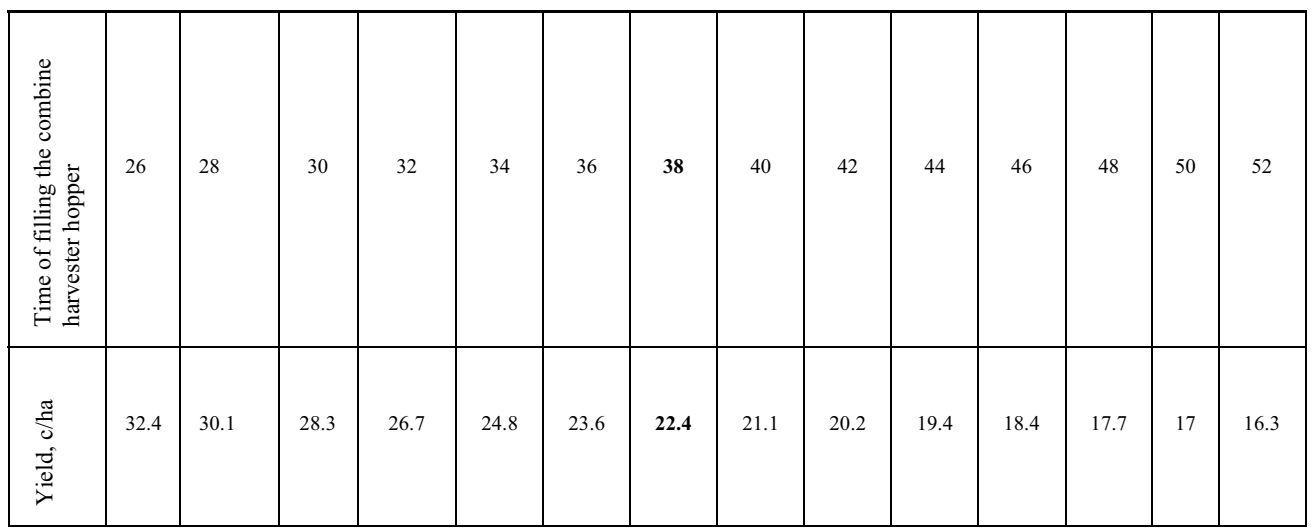

Using the same formula $(1,2,3)$ and the chart shown in Fig. 7 , we can quickly manage the work of the harvesting complex, i.e. make certain corrective actions both in terms of the number of combine harvesters and the number of vehicles.

To determine the number of vehicles needed to ensure optimal (without downtime) operation of the harvesting and transport complex, we use the following formula [5]: 


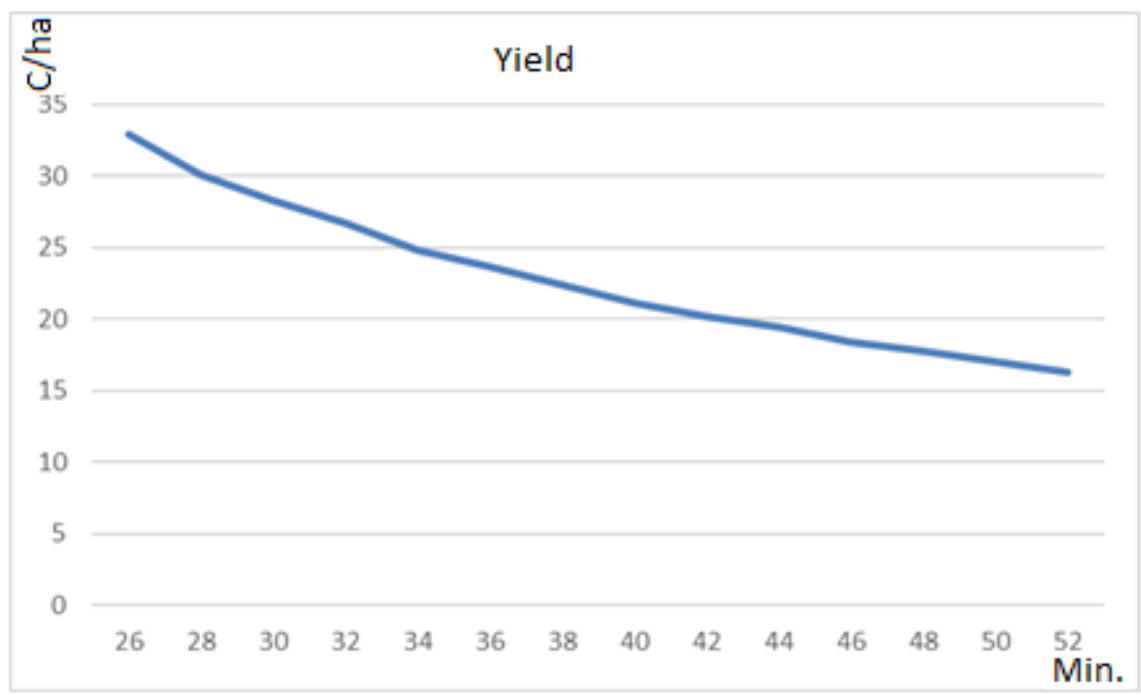

Fig. 7. The ratio of yield and time of the combine harvester filling.

$$
n_{v}^{1 c h}=\frac{\mathrm{C}_{1} \times \mathrm{T}_{W}}{q_{1} \times \mathrm{T}_{H}}
$$

where $n_{v}^{1 c h}-$ is the number of vehicles required to service one combine harvester, units;

$\mathrm{C}_{1}$ - weight of grain in the combine harvester hopper, $\mathrm{t}$;

$\mathrm{T}_{\mathrm{W}}$ - duration of the transport cycle, h.;

$\mathrm{q}_{1}$ - vehicle load capacity, $\mathrm{t}$;

$\mathrm{T}_{\mathrm{H}}$ - time of hopper filling with grain, $\mathrm{h}$.

$n_{v}^{1 c h}=\frac{6,05 \times 0,91}{24,2 \times 0,63}=0.36$ units.

$\mathrm{C}_{1}=\mathrm{V} \times \gamma=9 \times 0.672=6.05 \mathrm{t}$.

where, $\mathrm{V}$ is the volume of the combine harvester hopper, $\mathrm{m}^{3}$. In accordance with the operating instructions for the ACROS-580 combine harvester, the hopper capacity is $9 \mathrm{~m}^{3}$ with a hopper fill factor of 1.1 (with a transforming roof).

$\gamma$ - volume weight of barley $0.672 \mathrm{t} / \mathrm{m}^{3}$.

The load capacity of the KAMAZ-55102 car with a trailer is 24.2 tons.

To ensure the operation of the harvesting and transport complex (4 combines), 1.44 units are required, i.e. two cars. To increase the efficiency of the harvesting and transport complex, using elements of probability theory, it was proposed to reduce the number of cars to two. As a result, the downtime of cars waiting for combine harvesters unloading was reduced.

To derive the dependence of the number of vehicles on the yield (hopper filling time), we use the data from the chart in Fig. 7 and formula 4. These calculations are summarized in a table (table 2).

Table 2. The number of vehicles to ensure optimal operation of the harvesting complex, depending on the yield.

\begin{tabular}{|c|c|c|c|c|c|c|c|c|c|c|}
\hline \multirow{2}{*}{ Indicators } & \multicolumn{10}{|c|}{ Yield, c/ha } \\
\cline { 2 - 11 } & 20 & 24 & 28 & 32 & 36 & 40 & 44 & 48 & 52 & 56 \\
\hline $\begin{array}{c}\text { Number of } \\
\text { vehicles, units }\end{array}$ & 1.3 & 1.6 & 1.8 & 2.1 & 3.0 & 3.4 & 3.6 & 4.0 & 4.3 & 4.5 \\
\hline
\end{tabular}

For clearness, the data from table 2 will be presented as a chart. 


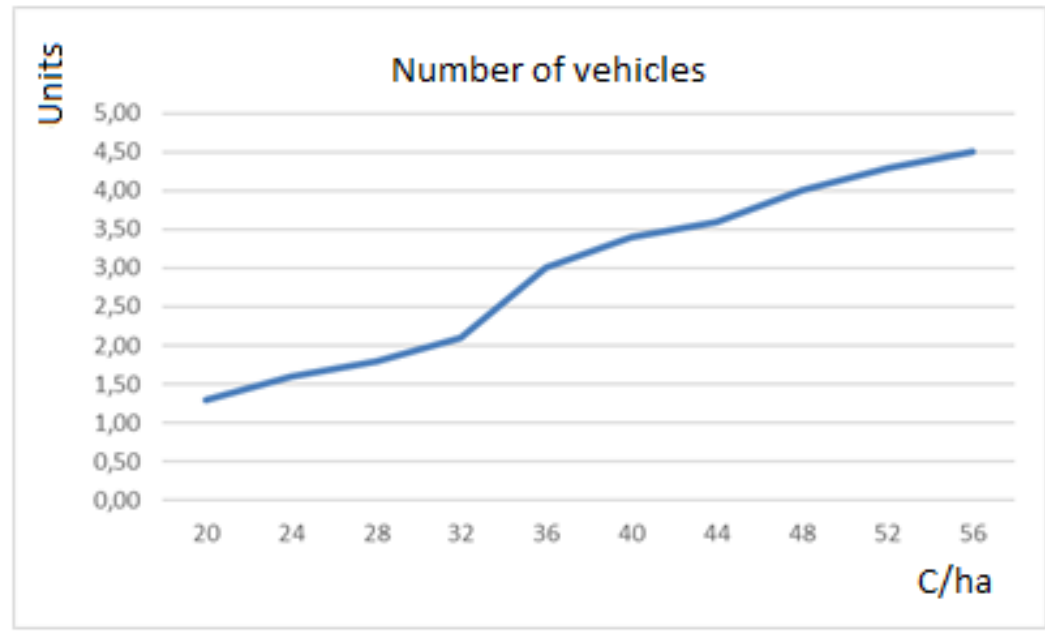

Fig. 8. The number of vehicles to ensure optimal operation of the harvesting complex, depending on the different yield.

Calculations for the number of vehicles were made at a distance of $10 \mathrm{~km}$ from the field to the warehouse. When forming the transport service of the harvesting and transport complex at other distances, it is necessary to apply the correction coefficients given in table 3 .

The correct acquisition and management of the harvesting and transport complex affects the economic indicators of the use of both combine harvesters and vehicles for taking out.

Research and analysis showed the following: the cost of transportation, at a constant distance from the field to the warehouse, affects the time of loading the vehicle with grain from the combine hopper (the time of unloading of one hopper is almost the same). In our study, the loading time of one car (4 hoppers) varied from 15 to 58 minutes. By accepting the cost of transportation for a vehicle loading time of 15 minutes $(0.25$ hour $)$ as a unit, we derived the following dependence of the cost of transportation on the time of loading of the vehicle and presented it in the form of a table (table 4).

Table 3. Correction factors for determination of the number of vehicles when servicing the harvesting complex at different distances from the field to the warehouse.

\begin{tabular}{|c|c|c|c|c|c|c|}
\hline Distance, $\mathrm{km}$ & Up to 5 & 10 & 15 & 20 & 25 & 30 \\
\hline $\begin{array}{c}\text { Correction } \\
\text { factor }\end{array}$ & 0.77 & 1.0 & 1.3 & 1.59 & 1.85 & 2.0 \\
\hline
\end{tabular}

For clearness, the increase in the cost of transportation, depending on the vehicle loading time, is presented in the form of a chart (Fig.8).

Table 4. Correction factors for increasing the cost of transportation depending on the vehicle loading time.

\begin{tabular}{|c|c|c|c|c|c|c|c|c|c|}
\hline $\begin{array}{c}\text { Loading time, } \\
\text { hour }\end{array}$ & 0.3 & 0.4 & 0.5 & 0.6 & 0.7 & 0.8 & 0.9 & 1.0 & 1.1 \\
\hline Correction factor & 1.0 & 1.03 & 1.04 & 1.06 & 1.08 & 1.11 & 1.12 & 1.15 & 1.18 \\
\hline
\end{tabular}




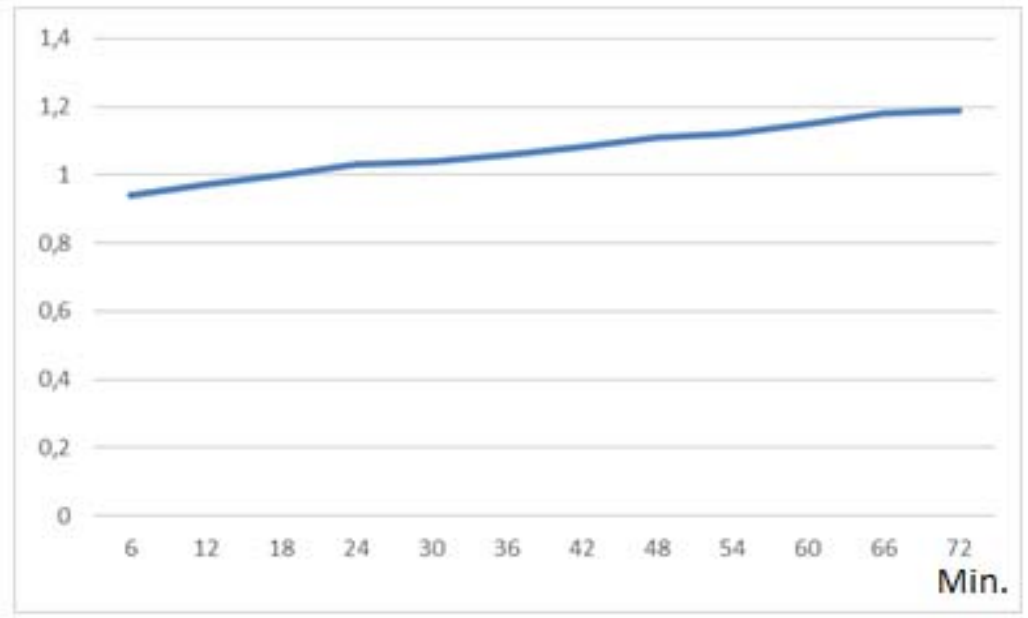

* Correction factors for $0.1 ; 0.2 ; 1.2$ hours $(6,12$ and 72 minutes $)$ are calculated.

Fig. 8. Coefficients for increasing the cost of transportation depending on the vehicle loading time.

The efficiency of using combine harvesters is determined by such a complete set and management of the work of the entire harvesting and transport complex, which provides for minimal downtime of combines while waiting for vehicles to unload grain hoppers. At the same time, combine harvesters must meet the requirements of intensity, productivity and efficiency during operation.

\section{Conclusion}

The problem of effective use of agricultural machinery has always been present, and it has become particularly relevant in the last 10-15 years, as a result of the decline in the fleet of agricultural machinery in Russian agricultural organizations, reduced production and reduced sales of agricultural machinery. Another reason for the need for more efficient use of equipment, in particular combine harvesters, is the strict agrotechnical terms of grain crops harvesting. If the timing is delayed, especially in areas of risky farming, there is shedding, spike sprouting, i.e. crop loss.

Agricultural machinery (tractors, grain - forage harvesters, etc.) has become more energyintensive, high-performance, high-tech and more expensive.

The organization of harvesting works went in the direction of creating harvesting and transport complexes, which include 4-6 combine harvesters, 3-4 units of vehicles, 1-2 units of balers, mobile maintenance facilities.

Therefore, questions of optimization of the composition of the harvesting and transport complex, questions of organization of the work of the HTC are in the circle of interests of domestic and foreign scientists.

The team of authors conducted long-term research on the optimization of the composition of HTC (research is ongoing) in agricultural organizations in the Middle Urals. In the course of the research the following was performed:

- Tabular forms were developed to collect the following information: hopper filling time; vehicle waiting time; time of hopper discharge into the vehicle; combine harvester driving time to the fold; waiting time of loading by a car after return from the warehouse; driving time of the car to the 1st combine harvester; time of discharge of the 1st combine harvester; waiting time of loading of the $n$-th hopper; driving time to $n$-th combine harvester; time of discharge of the n-th combine harvester; transport cycle time. 
- Mathematical expectation, variance and mean square deviation of indicators were calculated. Based on these indicators, the calculation and justification of the need to increase vehicles for grain transportation was performed.

- Yield of the harvested crop was calculated. For this purpose, this formula was used: $u$ $=10^{-4} \frac{Q_{H} \rho_{G} \lambda_{H}}{l_{W} \mathrm{~B} \beta}$. The estimated yield is $22.4 \mathrm{c} / \mathrm{ha}$; the actual yield is $22.7 \mathrm{c} / \mathrm{ha}$.

- Number of vehicles needed to ensure optimal operation of the harvesting unit was calculated. The following formula was used:

$n_{v}^{1 c h}=\frac{\mathrm{C}_{1} \times \mathrm{T}_{W}}{q_{1} \times \mathrm{T}_{H}}$.

- Recommendations for determining the optimal number of vehicles for transporting grain from combines were developed.

\section{References}

1. G.A. Iovlev, V.S. Zorkov, I.I. Goldina, Formation of the optimal composition of the harvesting complex using probability theory, Improving the design, operation and technical service of automotive and agricultural machinery, All-Russian Scientific and Practical Conference Collection of scientific papers edited by R. H. Avzalova, Ufa, Bashkir SAU, 132-142 (2016)

2. G.A. Iovlev, I.I. Goldina, Agro-food policy of Russia, 9, 34-37 (2016)

3. G.A. Iovlev, A.G. Nesgovorov, Theory and practice of world science, 5, 45-47 (2018)

4. A.S. Chulkov, Improving the efficiency of the harvesting and transport complex based on mobile vehicles with replaceable bodies when harvesting grain crops, The dissertation on competition of a scientific degree of candidate of technical sciences, AllRussian Research Institute of Agriculture Mechanization, Moscow (2013)

5. D.A. Muzylev, A.G. Kravtsov, N.V. Karnauh, N.G. Berezhnaya, O.V. Kutya Development of a method for selecting conditions for interaction between grainharvesting and transport complexes, http:// journals.uran.ua/

6. V.N. Lunyakin Optimization of harvesting-transport process of grain crops harvesting with the use of mobile load-transfer devic, http://disserr.ru/contents/57837.html

7. V.V. Abaev, KubSAU Scientific Journal, 70 (06), 2011

8. M.R. Mikhailov, Optimization of the use of combine harvesters by reliability parameters, DisserCat Scientific library of dissertations and abstracts http://www.dissercat.com/content/optimizatsiya-ispolzovaniya-zernouborochnykhkombainov-po-parametram-nadezhnosti\#ixzz5SdqMYC6p

9. V.S. Barnagyan, Increasing the efficiency of using agricultural machinery at machinetechnological stations, https://new-disser.ru/_avtoreferats/01003345229.pdf

10. V.D. Shepelev Justification of technical and technological consistency of harvestig and post-harvest processing of grain, https://new-disser.ru/_avtoreferats/01003314868.pdf

11. Random variables, htpp: www.skachatreferat.ru.

12. Discrete and continuous random variables, Distribution laws, http: www.kemsma.ru/mediawiki/images/3/3b.

13. A.N. Semin, Organization of harvesting and transport units (inf. p.) Sverdlovsk CSTI, 596-83, 4 (1983)

14. A.N. Semin, A.F. Novoselov Modeling of farms, 164 (Yekaterinburg, Ural University Publishing house together with "PIPP", 1992) 
15. Formula for vehicle performance calculation, Calculating the cost of transportation, https://studbooks.net/1512124/marketing/formula_rascheta_proizvoditelnosti_avtotran sporta_raschet_sebestoimosti_perevozok

16. Yu.V. Polishchuk, N.V. Laptev, A.P. Komarov, Agrarian Bulletin of the Urals, 05(196), 11-19 (2020) DOI: 10.32417/1997-4868-2020-196-5-11-19 (In Russian) 